\title{
Fatty liver largely explains associations of subclinical hypothyroidism with insulin resistance, metabolic syndrome, and subclinical coronary atherosclerosis
}

\author{
Carlos Posadas-Romero, Esteban Jorge-Galarza, Rosalinda Posadas-Sánchez, \\ Jorge Acuña-Valerio', Juan G Juárez-Rojas, Eric Kimura-Hayama², \\ Aida Medina-Urrutia and Guillermo C Cardoso-Saldaña
}

Endocrinology Department, ${ }^{1}$ Interventional Cardiology Department and ${ }^{2}$ Computed Tomography Department, Instituto Nacional de Cardiología 'Ignacio Chávez', Juan Badiano 1, Col. Sección XVI, C.P. 14080 Tlalpan, México D.F., Mexico

\author{
Correspondence \\ should be addressed \\ to C Posadas-Romero \\ Email \\ cposadasr@yahoo.com
}

\section{Abstract}

Background: The association of subclinical hypothyroidism (SCH) with insulin resistance, metabolic syndrome (MS), and coronary atherosclerosis is uncertain.

Objective: To investigate the role of increased intrahepatic fat in the association of SCH with insulin resistance, MS, and coronary atherosclerosis.

Design, patients, and methods: We conducted a cross-sectional study in a sample of 753 subjects ( $46 \%$ males) aged 35-70 years with no history of diabetes, renal, hepatic, thyroid, or coronary heart disease, and were participants of the Genetics of Atherosclerotic Disease study. SCH was defined as a high serum TSH level with normal free thyroxine concentration. Fatty liver (FL), coronary artery calcification (CAC), and abdominal visceral adipose tissue were assessed by computed tomography. Cross-sectional associations of $\mathrm{SCH}$ with and without $\mathrm{FL}$, with MS, insulin resistance, and subclinical atherosclerosis defined as a CAC score $>0$, were examined in logistic regression models.

Results: SCH was observed in $17.7 \%$ of the population studied. The prevalence of FL was similar in both euthyroid and $\mathrm{SCH}$ subjects ( 31.8 vs $27.8 \%, P=0.371$ ). SCH plus $\mathrm{FL}$ subjects were heavier and had more metabolic abnormalities compared with $\mathrm{SCH}$ plus normal liver subjects. In multivariate-adjusted logistic regression analyses, SCH plus FL was associated with MS (odds ratio (OR): $2.73,95 \% \mathrm{Cl}: 1.26-5.92$ ), insulin resistance (OR: $4.91,95 \% \mathrm{Cl}: 1.63-14.75)$, and CAC score $>0$ (OR: $3.05,95 \% \mathrm{Cl}$ : 1.20-7.76). SCH without FL showed no associations.

Conclusion: SCH with FL is associated with increased odds of MS, insulin resistance, and CAC, independent of potential confounders.

\section{Introduction}

Subclinical hypothyroidism ( $\mathrm{SCH}$ ), defined as an elevated serum thyroid-stimulating hormone (TSH) concentration and normal free thyroxine $\left(\mathrm{FT}_{4}\right)$ level, is a common condition with a reported prevalence between 4 and $20 \%$ (1). Increased hepatic fat content, in the absence of excessive alcohol consumption or other specific causes of steatosis, has been called non-alcoholic fatty liver disease (NAFLD) (2). At present, this condition is recognized as the most common liver disease, affecting $20-30 \%$ of the adult population (3). NAFLD is associated with a wide range of metabolic abnormalities, including glucose intolerance, dyslipidemia, and insulin resistance $(4,5)$, and also with atherosclerosis in coronary arteries (6). 
Whether or not $\mathrm{SCH}$ is related to cardiovascular risk factors and coronary heart disease (CHD) is controversial. Although some studies have reported associations of SCH with insulin resistance $(7,8)$, metabolic syndrome (MS) $(7,9)$, and CHD $(10,11)$, not all previous findings have been consistent $(12,13,14)$. Recent studies in adults $(9,15,16)$ and children (7) have shown that $\mathrm{SCH}$ is closely associated with NAFLD independent of potential confounders. Based on these findings and considering that insulin resistance is a key feature of NAFLD, we hypothesized that the relationship of $\mathrm{SCH}$ with cardiometabolic risk factors and CHD may be influenced by the presence of increased intrahepatic fat. To test this hypothesis, in this investigation, we analyzed the associations of $\mathrm{SCH}$ with and without fatty liver (FL) with insulin resistance, MS, and coronary artery calcification (CAC) score $>0$ as a surrogate marker for coronary atherosclerosis.

\section{Subjects and methods}

The study population included participants of the Genetics of Atherosclerotic Disease (GEA) study. The GEA study was designed to examine the genomic bases of CHD and assess relationships between traditional and emerging risk factors with clinical and subclinical atherosclerotic vascular diseases in an adult Mexican population (17). Briefly, a convenience sample of 1000 CHD patients and 1500 control subjects aged 35-70 years is being recruited from residents in Mexico City. Patients with established premature CHD were selected from the outpatient clinic of the National Institute of Cardiology. Volunteer control participants with a negative family history of premature CHD and no personal history of cardiovascular disease were recruited from blood bank donors, and through brochures posted in social service centers. Coronary patients and control subjects with a history of renal, liver, thyroid, or malignant disease, as well as those on treatment with corticosteroids, were excluded. The GEA study was approved by the Institutional Review Board of the National Institute of Cardiology and conducted according to the Declaration of Helsinki. Written informed consent was obtained from participants.

This study is a cross-sectional analysis of the baseline measurements of 1252 control subjects included in the GEA study from June 2008 to February 2013. None of the subjects were on medication therapy that could affect thyroid status. As diabetes is associated with higher incidence rates of FL and CAC (18), we excluded all subjects with type 2 diabetes $(n=155)$. Participants with alcohol consumption $\geq 20 \mathrm{~g} /$ day $(n=23)$, and those using statins $(n=89)$ or $\beta$-blockers $(n=48)$ were also excluded. We also excluded 184 subjects with unavailable insulin measurements. The final study population for this analysis comprised 753 subjects. When compared with the included participants, excluded participants with no insulin values were younger ( $53 \pm 9$ vs $50 \pm 9$ years old; $P<0.01)$ and had lower systolic blood pressure levels $(116 \pm 17$ vs $113 \pm 15 \mathrm{mmHg} ; P=0.042)$. No other differences were observed.

All participants in this study answered structured questionnaires that provide detailed information regarding family history, demographics, diet, physical activity, medications, smoking, and alcohol intake. Systolic and diastolic blood pressures were measured after subjects rested for at least $10 \mathrm{~min}$, and the average of the second and third measurements was used as the blood pressure of the subject. Height, weight, and waist circumference were measured and BMI was calculated as weight in kilograms divided by height in meters squared. The MS was defined using the criteria from the American Heart Association/ National Heart, Lung, and Blood Institute scientific statement on the MS (19), except for central obesity that was considered when waist circumference was $>90 \mathrm{~cm}$ in men and $>80 \mathrm{~cm}$ in women (20). Diabetes was defined by the American Diabetes Association criteria (21) and was also considered when participants reported glucoselowering treatment or a physician diagnosis of diabetes. Insulin resistance was estimated using the homeostasis model assessment (HOMA-IR). The presence of insulin resistance was considered when the HOMA-IR values were $\geq 75$ th percentile ( 3.58 in women and 3.12 in men). These cutoff points were obtained from a GEA study sample of 101 men and 180 women without obesity and with normal values of blood pressure and fasting glucose and lipids.

\section{Biochemical analyses}

Venous blood samples were collected from subjects after a 12-h fast. Plasma glucose, total cholesterol, triglycerides, HDL-C, aspartate aminotransferase (AST), and alanine aminotransferase (ALT) were measured in fresh samples, using standardized enzymatic procedures in a Hitachi 902 analyzer (Hitachi Ltd). Accuracy and precision of lipid measurements in our laboratory are under periodic surveillance by the Centers for Disease Control and Prevention service (Atlanta, GA, USA). LDL-C was estimated using the DeLong et al. formula (22). Total high-sensitivity C-reactive protein (hs-CRP) levels were 
determined by immunonephelometry on a BN Pro Spec nephelometer (Dade Behring GmbH, Marburg, Germany). Interassay coefficient of variation $(\mathrm{CV})$ values were $<6 \%$ for all of these assays. Plasma insulin concentrations were determined by a RIA (Millipore; RIA Kit, Cat. No. HI-14K, St Charles, MO, USA) the intra- and interassay $\mathrm{CV}$ values were 2.1 and $6.8 \%$ respectively.

Serum TSH and $\mathrm{FT}_{4}$ concentrations were measured by an electrochemiluminescent immunometric assay (Roche Diagnostics). TSH was considered normal if its value was between 0.3 and $4.5 \mathrm{mU} / 1$, on the basis of previous studies that demonstrated an increased clinical risk above this cutoff point $(23,24)$. SCH was considered if the TSH level was elevated and $\mathrm{FT}_{4}$ level was within the normal range (11.97-18.02 pmol/l) (25).

\section{Computed tomography study}

Visceral adipose tissue (VAT), subcutaneous fat, liver and spleen attenuation, and coronary artery calcium were quantified by computed tomography in each participant. Computed tomography of the chest and abdomen were performed using a 64-channel multidetector helical computed tomography system (Somatom Sensation, Siemens, Malvern, PA, USA) and interpreted by experienced radiologists. Scans were read to assess and quantify the following: i) total abdominal, subcutaneous, and VAT areas as described by Kvist et al. (26); ii) liver to spleen attenuation ratio (L:SAR) as described by Longo et al. (27); and iii) CAC score using the Agatston method (28). Subclinical atherosclerosis was defined as the presence of a CAC score $>0$ and hepatic steatosis as L:SAR $\leq 1.0$ (18).

\section{Statistical analysis}

Data are expressed as mean \pm s.D., median (interquartile range), or as frequencies for categorical variables. Comparisons were made using the $t$-test or the Mann-Whitney $U$ test, as appropriate, for continuous variables, and by $\chi^{2}$ analysis for categorical variables. The association of $\mathrm{SCH}$ with MS, insulin resistance, and CAC score $>0$ according to the presence of FL was assessed by multivariate logistic regression adjusted for age, gender, BMI, VAT, hs-CRP, $\mathrm{FT}_{4}$ and LDL-C. When the CAC score $>0$ was assessed as the dependent variable, we additionally adjusted for MS components: triglycerides, HDL-C, hypertension, and fasting glucose. In all models, euthyroid subjects without FL were used as a referent group. The MS was used instead of each MS component to avoid overadjustment. The values of $P<0.05$ were considered statistically significant. All statistical procedures were performed using the SPSS software (SPSS version 15.0, Inc.).

\section{Results}

A sample of 620 euthyroid subjects (31.8\% with FL) and 133 with SCH (27.8\% with FL) was analyzed. Except for age, number of females, and HDL-C concentrations, which were higher in SCH subjects, no other differences were observed in the comparison between euthyroid and $\mathrm{SCH}$ groups as a whole. Furthermore, the prevalence of FL across quartiles of TSH was not significantly different (Q1, 31.4\%; Q2, 33.3\%; Q3, 29.10\%; and Q4, 30.11\%, $X^{2}$ : 0.83). To determine the influence of FL on the association of SCH with MS, insulin resistance, and CAC score $>0$, euthyroid and $\mathrm{SCH}$ groups were stratified according to the presence of FL (with $(+)$ and without $(-)$ ). The anthropometric, clinical, and laboratory characteristics of the four groups are given in Table 1. Compared with euthyroid $\operatorname{FL}(-)$ subjects, those with $\mathrm{FL}(+)$, with or without $\mathrm{SCH}$, were significantly associated with a higher BMI, waist circumference, VAT, and higher values of triglycerides, total cholesterol/HDL-C, glucose, insulin, HOMA-IR, hs-CRP, ALT, AST, and lower concentrations of HDL-C. Moreover, except for non-HDL-C and hs-CRP values, no differences were found between euthyroid $\mathrm{FL}(+)$ and $\mathrm{SCH} \mathrm{FL}(+)$ subjects. In addition, as shown in Fig. 1, the prevalence of MS and elevated HOMA-IR was higher in $\mathrm{FL}(+)$ groups, whereas the CAC score $>0$ was higher only among subjects with $\mathrm{SCH} \mathrm{FL}(+)$. Notably, despite their higher age, SCH FL ( - ) subjects had a metabolic pattern (Table 1) and prevalences of MS, insulin resistance, and CAC score $>0$ similar to euthyroid $\mathrm{FL}(-)$ subjects (Fig. 1).

Logistic regression models were used to assess whether $\mathrm{SCH}$, with or without FL, was associated with MS, insulin resistance, and CAC score $>0$ (Table 2). Compared with the euthyroid $\mathrm{FL}(-)$ group, euthyroid $\mathrm{FL}(+)$ subjects were more likely to have MS and insulin resistance, independent of confounding factors, including their higher prevalence of visceral abdominal obesity (45 vs $79 \%$ respectively). However, subjects with the combination of SCH and $\mathrm{FL}(+)$ showed stronger associations with MS and insulin resistance. Additionally, only the latter subgroup showed a significant association with the presence of a CAC score $>0$, even after adjustment for multiple cardiovascular risk factors. On the other hand, the $\mathrm{SCH}$ $\mathrm{FL}(-)$ group did not show any association with cardiometabolic abnormalities or CAC score $>0$. Owing to the relatively small number of subjects, analyses by gender were not performed. 
Table 1 Clinical and biochemical characteristics of study subjects by thyroid function and FL. Values are expressed as mean \pm s.D., median (interquartile range), or $n(\%)$; $P$ values were obtained by the $t$-test, the Mann-Whitney $U$ test, or the $\chi^{2}$-test respectively.

\begin{tabular}{|c|c|c|c|c|c|c|}
\hline & \multicolumn{3}{|c|}{ Euthyroidism } & \multicolumn{3}{|c|}{ Subclinical hypothyroidism } \\
\hline & $\mathrm{FL}(-)(n=423)$ & $\mathrm{FL}(+)(n=197)$ & $P$ & $\mathrm{FL}(-)(n=96)$ & $\mathrm{FL}(+)(n=37)$ & $P$ \\
\hline Age (years) & $52 \pm 9.6$ & $51.80 \pm 8.15$ & NS & $56.1 \pm 8.4^{\dagger}$ & $53.24 \pm 8.25$ & NS \\
\hline Gender (female) & $234(55.3)$ & $88(\overline{44.7)}$ & 0.013 & $63(\overline{65} .6)$ & $22(\overline{59} .5)$ & NS \\
\hline BMI $\left(\mathrm{kg} / \mathrm{m}^{2}\right)$ & $27.3 \pm 4.3$ & $30.0 \pm 4.16$ & $<0.01$ & $27.6 \pm 3.9$ & $30.5 \pm 3.9^{\dagger}$ & $<0.001$ \\
\hline Waist circumference $(\mathrm{cm})$ & $91.5 \pm 12$ & $99.4 \pm 12$ & $<0.01$ & $91.5 \pm 10$ & $99.5 \pm 10^{\dagger}$ & $<0.001$ \\
\hline Visceral adipose tissue $\left(\mathrm{cm}^{2}\right)$ & $126(89-170)$ & $173(145-220)$ & $<0.01$ & $133(101-174)$ & $178(130-233)^{\dagger}$ & $<0.001$ \\
\hline Systolic blood pressure $(\mathrm{mmHg})$ & $115 \pm 18$ & $118 \pm 15$ & 0.025 & $116 \pm 19$ & $120 \pm 17$ & NS \\
\hline Diastolic blood pressure $(\mathrm{mmHg})$ & $71 \pm 9.4$ & $73.8 \pm 10$ & $<0.01$ & $71.0 \pm 10$ & $73.13 \pm 9.7$ & NS \\
\hline $\mathrm{TC}(\mathrm{mmol} / \mathrm{l})$ & $4.97 \pm 0.96$ & $4.97 \pm 1.01$ & NS & $5.05 \pm 0.88$ & $5.28 \pm 1.04$ & NS \\
\hline Triglycerides (mmol/l) & $1.44(1.10-1.99)$ & $1.79(1 . \overline{3} 6-2.46)$ & $<0.01$ & $1.44(1.13-1.97)$ & $1.84(1.58-2.91)^{\dagger}$ & $<0.001$ \\
\hline $\mathrm{HDL}-\mathrm{C}(\mathrm{mmol} / \mathrm{dl})$ & $1.20(0.98-1.48)$ & $1.03(0.88-1.27)$ & $<0.01$ & $1.30(1.09-1.50)$ & $1.07(0.91-1.27)$ * & $<0.001$ \\
\hline Non-HDL-C (mmol/l) & $3.63(3.11-4.22)$ & $3.83(3.24-4.35)$ & NS & $3.60(3.19-4.20)$ & $4.27(3.29-4.84)^{\dagger}$ & $<0.001$ \\
\hline TC/HDL-C & $4.0(3.3-4.9)$ & $4.7(3.9-5.6)$ & $<0.01$ & $3.8(3.2-4.9)$ & $4.6(4.0-6.0)^{\dagger}$ & $<0.001$ \\
\hline Fasting glucose (mmol/l) & $4.94 \pm 0.50$ & $5.22 \pm 0.56$ & $<0.01$ & $4.89 \pm 0.50$ & $5.33 \pm 0.61^{\dagger}$ & $<0.001$ \\
\hline Insulin $(\mu \mathrm{U} / \mathrm{ml})$ & $14.7(11-20)$ & $22.6(18-29)$ & $<0.01$ & $14.9(\overline{11}-19)$ & $25.7(17-28)^{\dagger}$ & $<0.001$ \\
\hline HOMA-IR & $3.1(2.2-4.5)$ & $5.2(3.8-7.0)$ & $<0.01$ & $3.0(2.4-4.2)$ & $5.6(4.4-6.9)^{\dagger}$ & $<0.001$ \\
\hline hs-CRP (nmol/l) & $12.9(6.7-25.7)$ & $19.2(10.5-38.1)$ & $<0.01$ & $11.8(6.7-22.9)$ & $33.7(14.3-52.4)^{\dagger}$ & $<0.001$ \\
\hline Alanine aminotransferase (U/l) & $21(16-27)$ & $34(24-51)$ & $<0.01$ & $20(15-27)$ & $29.5(25.5-42)^{\dagger}$ & $<0.001$ \\
\hline Aspartate aminotransferase (U/I) & $23(19-28)$ & $29(24-38)$ & $<0.01$ & $25(20-29)$ & $28.5(24.5-36)^{\dagger}$ & $<0.001$ \\
\hline Thyroid-stimulating hormone (mU/l) & $2.3(1.7-3.0)$ & $2.2(1.7-2.9)$ & NS & $6.18(5.1-8.3)^{\dagger}$ & $5.9(5.0-8.1)^{\dagger}$ & NS \\
\hline Free thyroxine $(\mathrm{pmol} / \mathrm{l})$ & $15.45(14.2-16.7)$ & $15.32(12.9-16.7)$ & NS & $14.67(13.4-15.5)^{\dagger}$ & $14.67(14.2-15.45)^{*}$ & NS \\
\hline Alcohol (g/day) & $1.0(0.38-4.7)$ & $1.58(0.48-4.4)$ & NS & $0.38(0.38-1.9)^{*}$ & $0.96(0.38-4.7)$ & NS \\
\hline
\end{tabular}

FL, fatty liver; TC, total cholesterol; HOMA-IR, homeostasis model assessment of insulin resistance; hs-CRP, high-sensitivity $\mathrm{C}$-reactive protein. ${ }^{*} P<0.05$, ${ }^{+} P<0.01$ vs euthyroidism $\mathrm{FL}(-)$.

\section{Discussion}

SCH is closely associated with FL, independent of known metabolic risk factors $(7,9)$. However, there is no clear explanation for this association. It has been suggested that obesity-related SCH $(29,30)$, and the altered lipid peroxidation (31), which is one of the leading causes of liver cell damage (32), might play a role in the association between hypothyroidism and hepatic steatosis. On the other hand, an increase in fatty acids in hepatic steatosis might inhibit $\mathrm{T}_{4}$ to tri-iodothyronine conversion, which in turn perpetuates fat accumulation in the liver (15). The possibility that insulin resistance and MS result in hepatic lipid accumulation and FL in the $\mathrm{SCH}$ subjects cannot be excluded by the results of this study. Thus, at present, the question of causality remains unanswered. Regardless of the direction of causality, the novel findings of this study are that, compared with euthyroid and SCH individuals without FL, subjects with $\mathrm{SCH} F(+)$ had a significantly higher prevalence of abdominal obesity, VAT excess,

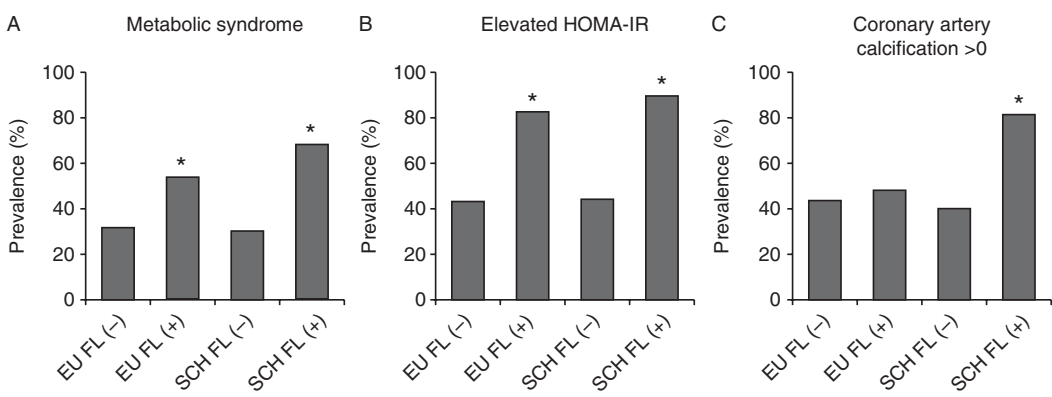

\section{Figure 1}

Prevalence of metabolic syndrome (A), elevated HOMA-IR (B), and coronary artery calcification $>0(C)$, according to thyroid function and fatty liver. $\mathrm{EU}$, euthyroidism; $\mathrm{SCH}$, subclinical hypothyroidism; $\mathrm{FL}(-)$, without fatty liver; $\mathrm{FL}(+)$, with fatty liver. ${ }^{*} P<0.001$ vs $\mathrm{EU} \mathrm{FL}(-)$, using $\chi^{2}$-test. 
Table 2 Association of thyroid function with metabolic syndrome, insulin resistance, and coronary artery calcification according to the presence of FL. Values are expressed as odds ratios $(95 \% \mathrm{Cl})$, obtained by multivariate logistic regression analyses.

\begin{tabular}{|c|c|c|c|}
\hline & $\begin{array}{l}\text { Metabolic } \\
\text { syndrome }\end{array}$ & $\begin{array}{l}\text { HOMA-IR } \\
\text { elevated }\end{array}$ & $\begin{array}{l}\text { Coronary } \\
\text { artery } \\
\text { calcification } \\
\text { score }>0\end{array}$ \\
\hline \multicolumn{4}{|l|}{ Model $1^{a}$} \\
\hline EU FL(-) & Reference & Reference & Reference \\
\hline $\mathrm{EU} \mathrm{FL}(+)$ & $1.63(1.11-2.39)$ & $4.34(2.79-6.80)$ & $0.87(0.54-1.41)$ \\
\hline $\mathrm{SCH} F L(-)$ & $0.92(0.55-1.54)$ & $1.01(0.62-1.65)$ & $0.78(0.42-1.48)$ \\
\hline $\mathrm{SCH} \mathrm{FL}(+)$ & $3.28(1.56-6.94)$ & $7.23(2.40-21.83)$ & $2.75(1.18-6.42)$ \\
\hline \multicolumn{4}{|c|}{ Model $2^{\mathrm{b}}$} \\
\hline EU FL(-) & Reference & Reference & Reference \\
\hline EU FL(+) & $1.63(1.11-2.39)$ & $3.83(2.43-6.05)$ & $1.02(0.61-1.69)$ \\
\hline SCH FL(-) & $0.89(0.53-1.53)$ & $0.93(0.55-1.57)$ & $0.73(0.37-1.43)$ \\
\hline $\mathrm{SCH} \mathrm{FL}(+)$ & $2.73(1.26-5.92)$ & $4.91(1.63-14.75)$ & $3.05(1.20-7.76)$ \\
\hline
\end{tabular}

${ }^{a}$ Model 1: adjusted for age, gender, and BMI.

${ }^{b}$ Model 2: adjusted for age, gender, BMI, visceral adipose tissue, highsensitivity C-reactive protein, free thyroxine, and LDL-C. Additional adjustment for metabolic syndrome components - triglycerides, HDL-C hypertension, and fasting glucose - was done in the coronary artery calcification score $>0$. EU, euthyroidism; FL, fatty liver; $\mathrm{SCH}$, subclinical hypothyroidism

elevated triglycerides, low HDL-C, insulin resistance, MS, and, most importantly, subclinical atherosclerosis defined as a CAC score $>0$. Moreover, multivariate regression analyses revealed that the presence of $\mathrm{SCH}$ plus $\mathrm{FL}$ was associated with MS, insulin resistance, and CAC score $>0$, independent of confounding factors. The finding that $\mathrm{SCH}$ subjects without FL did not show any of these relationships suggests that increased hepatic fat, not low thyroid function, is responsible for the associations observed.

The results from previous studies investigating the association of mild thyroid failure with insulin resistance, MS, and CHD are conflicting. SCH subjects have been shown to have similar (13), higher $(7,8)$, or lower (12) insulin and HOMA-IR levels, compared with euthyroid control subjects. Similarly, Garduño-Garcia et al. (13) found that the prevalence of MS was not different between SCH subjects and individuals with normal thyroid function, while another study demonstrated that the syndrome was significantly more prevalent in subjects with both overt thyroid failure and SCH than in euthyroid subjects (9). Interestingly, a very recent study conducted in overweight and obese children has demonstrated a multivariate-adjusted association of $\mathrm{SCH}$ with insulin resistance and MS (7). Notably, in that study, FL was significantly more prevalent in $\mathrm{SCH}$ patients than in euthyroid subjects, suggesting a possible role of the increased hepatic fat in the associations (7). With regard to cardiovascular disease, some $(10,33)$, but not all $(14,34)$, published studies have reported associations between SCH and CHD. An interesting recent study by Sert et al. (35) has demonstrated that obese adolescents with FL and SHC had a proatherogenic metabolic risk factor profile and a higher carotid intimamedia thickness and left ventricular mass. Our results obtained for adults confirm the observations of that study. Inconsistencies among studies may be explained by the differences in the study design, sample size, characteristics of the populations studied, and criteria used to define thyroid dysfunction. However, our finding that only SCH patients with FL showed significant positive correlations with metabolic abnormalities and subclinical atherosclerosis, even after adjustment for confounding factors including abdominal VAT, suggests that increased hepatic fat may contribute directly to the association of $\mathrm{SCH}$ with these conditions, and that the discrepant results among previous studies investigating relationships between $\mathrm{SCH}$ and metabolic factors could reflect varying severity and prevalence of FL both between subjects within studies and between studies.

The role of FL as a factor influencing the association of $\mathrm{SCH}$ with cardiometabolic risk factors and the presence of a CAC score $>0$ is supported by studies demonstrating that an increased intrahepatic fat content is associated with these conditions. In an investigation conducted in 2589 individuals, Speliotes et al. (36) found that after adjustment for VAT and other fat depots, FL measured by computed tomography was significantly associated with diabetes, hypertension, impaired fasting glucose, MS, HDL-C, triglycerides, and adiponectin levels. In another study using euglycemic hyperinsulinemic clamps, Fabbrini et al. (37) found a significantly greater insulin resistance in liver, adipose, and muscle tissues from obese subjects with NAFLD compared with that observed in obese subjects without NAFLD, even though the two groups had been matched for VAT volume. With regard to the association between FL and CAC score $>0$, two recent studies involving large numbers of subjects showed that the association remained significant after controlling for traditional cardiovascular risk factors, including VAT (38) or pre-existing cardiovascular disease (39). Taken together, our results and those of other studies (36, $37,38,39)$ strongly suggested that hepatic fat is intimately involved in the pathogenesis of metabolic abnormalities and subclinical atherosclerosis present in subjects with FL. The adverse cardiovascular risk profile found in subjects with SCH plus FL may serve as a marker of long-term cardiovascular risk and may explain some of the previously observed associations between $\mathrm{SCH}$ and cardiovascular disease $(10,33)$. 


\section{Limitations}

This study has some potential limitations. First, because of the cross-sectional nature of this study and the relatively small number of subjects with SCH and FL, caution should be exercised in interpreting our findings, which should be considered as a hypothesis generated and confirmed by studies with a larger number of subjects. Secondly, the diagnosis of FL was performed by CT scans with the exclusion of viral hepatitis B and C. HIV/AIDS, syphilis, and Chagas disease were also excluded. However, other causes of potential abnormality in liver density measured by CT such as viral hepatitis A, D, E, and G, autoimmune hepatitis, metabolic liver disease, anti-trypsin deficiency, Wilson's disease, hemocromatosis, and celiac disease were not excluded. Thirdly, the diagnosis of FL by CT was not confirmed by liver biopsies. However, a significant correlation has been demonstrated between the liver attenuation images on CT and the histological grade of steatosis (40). Fourthly, we did not measure insulin resistance by more sophisticated approaches such as the euglycemic clamp; however, the HOMA index has proven to be a reliable measure of insulin sensitivity in non-diabetics (41).

\section{Conclusions}

In summary, our data strongly suggest that in subjects with $\mathrm{SCH}$, the increased liver fat content, and not low thyroid function, is more predictive of metabolic abnormalities and the presence of CAC, a surrogate marker of atherosclerosis. Further clinical and experimental studies may be warranted to validate our findings and determine whether correction of FL could contribute to the improvement of the metabolic derangement and reduce cardiovascular risk.

Declaration of interest

The authors declare that there is no conflict of interest that could be perceived as prejudicing the impartiality of the research reported.

\section{Funding}

This work was supported by a grant from Mexico's Consejo Nacional de Ciencia y Tecnología (project \# SALUD-2010-2-150537).

\section{Author contribution statement}

C Posadas-Romero, E Jorge-Galarza., R Posadas-Sánchez, and E KimuraHayama participated in conception, design, analysis, interpretation of data, and the final approval of the manuscript submitted. J Acuña-Valerio, J G Juárez-Rojas, A Medina-Urrutia, and G C Cardoso-Saldaña drafted the manuscript and revised it critically for important content.

\section{Acknowledgements}

The authors thank all staff and subjects who participated in this study.

\section{References}

1 Cooper DS \& Biondi B. Subclinical thyroid disease. Lancet 2012379 1142-1154. (doi:10.1016/S0140-6736(11)60276-6)

2 Stefan N, Kantartzis K \& Häring H-U. Causes and metabolic consequences of fatty liver. Endocrine Reviews 200829 939-960. (doi:10.1210/er.2008-0009)

3 Browning JD, Szczepaniak LS, Dobbins R, Nuremberg P, Horton JD, Cohen JC, Grundy SM \& Hobbs HH. Prevalence of hepatic steatosis in an urban population in the United States: impact of ethnicity. Hepatology 200440 1387-1395. (doi:10.1002/hep.20466)

4 Korenblat KM, Fabbrini E, Mohammed BS \& Klein S. Liver, muscle, and adipose tissue insulin action is directly related to intrahepatic triglyceride content in obese subjects. Gastroenterology $2008 \mathbf{1 3 4}$ 1369-1375. (doi:10.1053/j.gastro.2008.01.075)

5 Ginsberg HN, Zhang YL \& Hernandez-Ono A. Metabolic syndrome: focus on dyslipidemia. Obesity 200614 (Suppl 1) 41S-49S. (doi:10.1038/ oby.2006.281)

6 Assy N, Djibre A, Farah R, Grosovski M \& Marmor A. Presence of coronary plaques in patients with nonalcoholic fatty liver disease. Radiology 2010254 393-400. (doi:10.1148/radiol.09090769)

7 Pacifico L, Bonci E, Ferraro F, Andreoli G, Bascetta S \& Chiesa C. Hepatic steatosis and thyroid function tests in overweight and obese children. International Journal of Endocrinology 20132013 1-8. (doi:10.1155/2013/ 381014)

8 Maratou E, Hadjidakis DJ, Kollias A, Tsegka K, Peppa M, Alevizaki M, Mitrou P, Lambadiari V, Boutati E, Nikzas D et al. Studies of insulin resistance in patients with clinical and subclinical hypothyroidism. European Journal of Endocrinology 2009160 785-790. (doi:10.1530/ EJE-08-0797)

9 Chung GE, Kim D, Kim W, Yim JY, Park MJ, Kim YJ, Yoon JH \& Lee HS. Non-alcoholic fatty liver disease across the spectrum of hypothyroidism. Journal of Hepatology 201257 150-156. (doi:10.1016/j.jhep.2012.02.027)

10 Walsh JP, Bremner AP, Bulsara MK, O’Leary P, Leedman PJ, Feddema P $\&$ Michelangeli V. Subclinical thyroid dysfunction as a risk factor for cardiovascular disease. Archives of Internal Medicine 2005165 2467-2472. (doi:10.1001/archinte.165.21.2467)

11 Razvi S, Weaver JU, Vanderpump MP \& Pearce SH. The incidence of ischemic heart disease and mortality in people with subclinical hypothyroidism: reanalysis of the Whickham Survey cohort. Journal of Clinical Endocrinology and Metabolism 201095 1734-1740. (doi:10.1210/ jc.2009-1749)

12 Chen G, Wu J, Lin Y, Huang B, Yao J, Jiang Q, Wen J \& Lin L. Associations between cardiovascular risk, insulin resistance, $\beta$-cell function and thyroid dysfunction: a cross-sectional study in She ethnic minority group of Fujian Province in China. European Journal of Endocrinology 2010163 775-782. (doi:10.1530/EJE-10-0710)

13 Garduño-Garcia Jde J, Alvirde-Garcia U, López-Carrasco G, Padilla Mendoza ME, Mehta R, Arellano-Campos O, Choza R, Sauque L, GaraySevilla ME, Malacara JM et al. TSH and free thyroxine concentrations are associated with differing metabolic markers in euthyroid subjects. European Journal of Endocrinology 2010163 273-278. (doi:10.1530/ EJE-10-0312)

14 Cappola AR, Fried LP, Arnold AM, Danese MD, Kuller LH, Burke GL, Tracy RP \& Ladensos PW. Thyroid status, cardiovascular risk, and mortality in older adults. Journal of the American Medical Association 2006295 1033-1041. (doi:10.1001/jama.295.9.1033)

15 Ittermann T, Haring R, Wallaschofski H, Baumeister SE, Nauck M, Dörr M, Lerch MM, Meyer zu Schwabedissen HE, Rosskopf D \& Völzke H. Inverse association between serum free thyroxine levels 
and hepatic steatosis: results from the Study of Health in Pomerania. Thyroid 201222 568-574. (doi:10.1089/thy.2011.0279)

16 Pagadala MR, Zein CO, Dasarathy S, Yerian LM, Lopez R \& McCullough AJ. Prevalence of hypothyroidism in nonalcoholic fatty liver disease. Digestive Diseases and Sciences 201257 528-534. (doi:10.1007/s10620-011-2006-2)

17 Villarreal-Molina T, Posadas-Romero C, Romero-Hidalgo S, AntúnezArgüelles E, Bautista-Grande A, Vargas-Alarcón G, Kimura-Hayama E, Canizales-Quinteros S, Juárez-Rojas JG, Posadas-Sánchez R et al. The $\mathrm{ABCA} 1$ gene $\mathrm{R} 230 \mathrm{C}$ variant is associated with decreased risk of premature coronary artery disease: the genetics of atherosclerotic disease (GEA) study. PLoS ONE 20127 e49285. (doi:10.1371/journal.pone.0049285)

18 McKimmie RL, Daniel KR, Carr JJ, Bowden DW, Freedman BI, Register TC, Hsu FC, Lohman KK, Weinberg RB \& Wagenknecht LE. Hepatic steatosis and sub-clinical cardiovascular disease in a cohort enriched for type 2 diabetes: the Diabetes Heart Study. American Journal of Gastroenterology 2008103 3029-3035. (doi:10.1111/j.1572-0241.2008.02188.x)

19 Grundy SM, Cleeman JI, Daniels SR, Donato KA, Eckel RH, Franklin BA, Donato KA, Eckel RH, Franklin BA, Gordon DJ et al. American Heart Association; National Heart, Lung, and Blood Institute Diagnosis and management of the metabolic syndrome: an American Heart Association/National Heart, Lung, and Blood Institute Scientific Statement. Circulation 2005112 2735-2752. (doi:10.1161/CIRCULATIONAHA.105. 169404)

20 Sánchez-Castillo CP, Velázquez-Monroy O, Berber A, Lara-Esqueda A, Tapia-Conyer R \& James WP. Anthropometric cutoff points for predicting chronic diseases in the Mexican National Health Survey 2000. Obesity Research 200311 442-451. (doi:10.1038/oby.2003.60)

21 American Diabetes Association. Diagnosis and classification of diabetes mellitus. Diabetes Care 200932 s62-s67. (doi:10.2337/dc09-S062)

22 DeLong DM, DeLong ER, Wood PD, Lippel K \& Rifkind BM. A comparison of methods for the estimation of plasma low- and very low-density lipoprotein cholesterol. The Lipid Research Clinics Prevalence Study. Journal of the American Medical Association 1986256 2372-2377. (doi:10.1001/jama.1986.03380170088024)

23 Rodondi N, Bauer DC, Cappola AR, Cornuz J, Robbins J, Fried LP, Ladenson PW, Vittinghoff E, Gottdiener JS \& Newman AB. Subclinical thyroid dysfunction, cardiac function, and the risk of heart failure. The Cardiovascular Health study. Journal of the American College of Cardiology 200852 1152-1159. (doi:10.1016/j.jacc.2008.07.009)

24 Rodondi N, Den Elzen WPJ, Bauer DC, Cappola AR, Razvi S, Walsh JP, Asvold BO, Iervasi G, Imaizumi M, Collet TH et al. Subclinical hypothyroidism and the risk of coronary heart disease and mortality. Journal of the American Medical Association 2010304 1365-1374. (doi:10.1001/jama.2010.1361)

25 Nanchen D, Gussekloo J, Westendorp RG, Stott DJ, Jukema JW, Trompet S, Ford I, Welsh P, Sattar N, Macfarlane PW et al. Subclinical thyroid dysfunction and the risk of heart failure in older persons at high cardiovascular risk. Journal of Clinical Endocrinology and Metabolism 2012 97 852-861. (doi:10.1210/jc.2011-1978)

26 Kvist H, Chowdhury B, Grangård U, Tylén U \& Sjöström L. Total and visceral adipose-tissue volumes derived from measurements with computed tomography in adult men and women: predictive equations. American Journal of Clinical Nutrition 198848 1351-1361.

27 Longo R, Ricci C, Masutti F, Vidimari R, Crocé LS, Bercich L, Tiribelli C $\&$ Dalla Palma L. Fatty infiltration of the liver. Quantification by $1 \mathrm{H}$ localized magnetic resonance spectroscopy and comparison with computed tomography. Investigative Radiology 199328 297-302. (doi:10.1097/00004424-199304000-00006)
28 Mautner GC, Mautner SL, Froehlich J, Feuerstein IM, Proschan MA, Roberts WC \& Doppman JL. Coronary artery calcification: assessment with electron beam CT and histomorphometric correlation. Radiology 1994192 619-623. (doi:10.1148/radiology.192.3.8058924)

29 Knudsen N, Laurberg P, Rasmussen LB, Bülow I, Perrild H, Ovesen L \& Jørgensen T. Small differences in thyroid function may be important for body mass index and the occurrence of obesity in the population. Journal of Clinical Endocrinology and Metabolism 200590 4019-4024. (doi:10.1210/jc.2004-2225)

30 Nyrnes A, Jorde R \& Sundsfjord J. Serum TSH is positively associated with BMI. International Journal of Obesity 200630 100-105. (doi:10.1038/sj.ijo.0803112)

31 Sundaram V, Hanna AN, Koneru L, Newman HA \& Falko JM. Both hypothyroidism and hyperthyroidism enhance low density lipoprotein oxidation. Journal of Clinical Endocrinology and Metabolism 199782 3421-3424. (doi:10.1210/jcem.82.10.4315)

32 Poli G, Albano E \& Dianzani MU. The role of lipid peroxidation in liver damage. Chemistry and Physics of Lipids 198745 117-142. (doi:10.1016/ 0009-3084(87)90063-6)

33 Tièche M, Lupi GA, Gutzwiller F, Grob PJ, Studer H \& Bürgi H. Borderline low thyroid function and thyroid autoimmunity. Risk factors for coronary heart disease? British Heart Journal 198146 202-206. (doi:10.1136/hrt.46.2.202)

34 Imaizumi M, Akahoshi M, Ichimaru S, Nakashima E, Hida A, Soda M, Usa T, Ashizawa K, Yokoyama N, Maeda R et al. Risk for ischemic heart disease and all-cause mortality in subclinical hypothyroidism. Journal of Clinical Endocrinology and Metabolism 200489 3365-3370. (doi:10.1210/ jc.2003-031089)

35 Sert A, Pirgon O, Aypar E, Yilmaz H \& Odabas D. Subclinical hypothyroidism as a risk factor for the development of cardiovascular disease in obese adolescents with nonalcoholic fatty liver disease. Pediatric Cardiology 201334 1166-1174. (doi:10.1007/s00246-013-0638-z)

36 Speliotes EK, Massaro JM, Hoffmann U, Vasan RS, Meigs JB, Sahani DV, Hirschhorn JN, O'Donnell CJ \& Fox CS. Fatty liver is associated with dyslipidemia and dysglycemia independent of visceral fat: the Framingham Heart Study. Hepatology 201051 1979-1987. (doi:10.1002/hep.23593)

37 Fabbrini E, Magkos F, Mohammed BS, Pietka T, Abumrad NA, Patterson BW, Okunade A \& Klein S. Intrahepatic fat, not visceral fat, is linked with metabolic complications of obesity. PNAS 2009106 15430-15435. (doi:10.1073/pnas.0904944106)

38 Liu J, Musani SK, Bidulescu A, Carr JJ, Wilson JG, Taylor HA \& Fox CS. Fatty liver, abdominal adipose tissue and atherosclerotic calcification in African Americans: the Jackson Heart Study. Atherosclerosis 2012224 521-525. (doi:10.1016/j.atherosclerosis.2012.07.042)

39 Sung KC, Wild SH, Kwag HJ \& Byrne CD. Fatty liver, insulin resistance, and features of metabolic syndrome: relationships with coronary artery calcium in 10,153 people. Diabetes Care 201235 2359-2364. (doi:10.2337/dc12-0515)

40 Limanond P, Raman SS, Lassman C, Sayre J, Ghobrial RM, Busuttil RW, Saab S \& Lu DS. Macrovesicular hepatic steatosis in living related liver donors: correlation between CT and histologic findings. Radiology 2004230 276-280. (doi:10.1148/radiol. 2301021176)

41 Bonora E, Targher G \& Alberiche M. Homeostasis model assessment closely mirrors the glucose clamp technique in the assessment of insulin sensitivity: studies in subjects with various degrees of glucose tolerance and insulin sensitivity. Diabetes Care 200023 57-63. (doi:10.2337/diacare.23.1.57)

Received 20 February 2014

Revised version received 19 May 2014

Accepted 10 June 2014 